\title{
Guest editorial for EMMSAD'2017 special section
}

\author{
Iris Reinhartz-Berger ${ }^{1} \cdot$ Wided Guédria ${ }^{2} \cdot$ Palash Bera ${ }^{3}$ \\ Received: 12 August 2018 / Accepted: 13 August 2018 / Published online: 24 August 2018 \\ c) Springer-Verlag GmbH Germany, part of Springer Nature 2018
}

The EMMSAD (Exploring Modeling Methods for Systems Analysis and Development) series has produced 22 events, associated with CAiSE (Conference on Advanced Information Systems Engineering), from 1996 to 2017. From 2009, EMMSAD has become a 2-day working conference. The topics addressed by the EMMSAD series focus on modeling methods for software systems, enterprises, and business processes, as well as their evaluation through a variety of empirical and non-empirical approaches. The aims, topics, and history of EMMSAD can be found on the Web site at http://www.emmsad.org/.

\section{Scope}

This special section follows the 22nd edition of the EMMSAD series, organized in conjunction with CAiSE'17 at Essen, Germany, June 2017. A total of 25 submissions from 18 countries were received, and 9 full papers and 2 short papers were selected and published in Springer LNBIP 287 volume. These papers referred to: (1) modeling approaches that support decision making, business process or behavior specification, and evolving contexts of enterprise modeling and cloud computing; and (2) evaluation and comparison of modeling languages and methods.

Information and software systems development has resulted in a rich heritage of modeling methods and notations for software and information systems development [3], enterprise management [2], and business process management [1]. This set of methods and notations continues to be enriched with extensions, refinements, and even new languages, to deal with new challenges. Despite the attempts of standardization (e.g., UML [4, 5]/SysML [7] for software/systems

\footnotetext{
Iris Reinhartz-Berger

iris@is.haifa.ac.il

1 University of Haifa, Haifa, Israel

2 Luxembourg Institute of Science and Technology - LIST, Esch-sur-Alzette, Luxembourg

3 Saint Louis University, St. Louis, USA
}

design, ArchiMate [8] for enterprise architecture modeling, and BPMN [6] for business process modeling), new modeling methods are constantly being introduced. These especially aim to deal with emerging trends such as compliance and regulations, cloud computing, big data, business analytics, and the Internet of Things. These ongoing changes significantly impact the way information and software systems, enterprises, and business processes are being analyzed, designed, and deployed in practice.

A wide range of available modeling methods call for their evaluation. Evaluation of modeling methods contributes to the knowledge and understanding of their strengths and weaknesses. This knowledge may guide researchers toward the development of the next generation of modeling methods and help practitioners select the modeling methods that are most appropriate to their needs. A variety of evaluation approaches can be found in the literature, including feature comparison, theoretical and conceptual investigation, and empirical evaluation [9].

EMMSAD'2017 provided a forum for researchers and practitioners interested in topics related to exploration and evaluation of modeling methods for systems analysis and development to meet and exchange research ideas and results. This special section presents extended versions of five papers accepted to EMMSAD'2017 and invited to extend their contributions to this special section.

\section{The papers selected for this special section}

All papers in this special section deal with evaluation or comparison of modeling approaches:

1. Dirk van der Linden, Irit Hadar, and Anna Zamansky. "What practitioners really want: requirements for visual notations in conceptual modeling" reports on a survey conducted with practitioners in order to elicit their requirements for visual notations of modeling languages.

2. Kurt Sandkuhl and Ulf Seigerroth. "Method engineering in information systems analysis and design: a balanced 
scorecard approach for method improvement" presents evaluation criteria and corresponding metrics for improving and creating new modeling methods.

3. Drazen Brdjanin, Goran Banjac, Danijela Banjac, and Slavko Maric. "An experiment in model-driven conceptual database design" presents the design and the results of a controlled experiment for evaluating an approach to automatic design of the initial conceptual database model based on collaborative business process models.

4. Arnon Sturm, Jumana Nassour, Michael Elhadad, and Eric Yu. "Evaluating the comprehension of ME-maps" deals with the design and results of an empirical evaluation of the effectiveness of a knowledge representation technique called ME-maps.

5. Afef Awadid, Selmin Nurcan, and Sonia Ayachi Ghannouchi, "On leveraging the fruits of research efforts in the arena of business process modeling formalisms: a map-driven approach for decision making" provides guidelines for business process modeling formalism selection based on a systematic literature review.

Acknowledgements We wish to thank the following reviewers from the EMMSAD'2017 Program Committee for their timely and valuable reviews during the two-round review process for this special section: Neil Ernst, Kathrin Figl, Mohamad Gharib, Sérgio Guerreiro, Giancarlo Guizzardi, Stijn Hoppenbrouwers, Jennifer Horkoff, John Krogstie, Raimundas Matulevicius, Haralambos Mouratidis, John Mylopoulos, Andreas L. Opdahl, Oscar Pastor Lopez, Pericles Loucopoulos, Henderik A. Proper, Barbara Pernici, Jolita Ralyté, Janis Stirna, Arnon Sturm, Anna Zamansky, and Jelena Zdravkovic. We would also like to thank the Editors-in-Chief of the Journal of Software and Systems Modeling, Jeff Gray and Bernhard Rumpe, for accepting our request to publish this special section of EMMSAD for the first time. We particularly would like to thank Martin Schindler for his support, help, and patience. Finally, our gratitude goes to all authors of the selected papers who made this special section possible by submitting their work and revising it according to the reviewers' and editors' comments.

\section{References}

1. Aldin, L., de Cesare, S.: A literature review on business process modelling: new frontiers of reusability. Enterp. Inf. Syst. 5(3), 359-383 (2011)

2. Braun, R.: Towards the state of the art of extending enterprise modeling languages. In: 3rd IEEE International Conference on Model-Driven Engineering and Software Development (MODELSWARD' 2015), pp. 1-9 (2015)

3. Buede, D.M., Miller, W.D.: The Engineering Design of Systems: Models and Methods. Wiley, New York (2016)

4. ISO/IEC 19505-1:2012: Information technology—object management group unified modeling language (OMG UML). Part 1: infrastructure

5. ISO/IEC 19505-2:2012: Information technology—object management group unified modeling language (OMG UML). Part 2: superstructure

6. ISO/IEC 19510:2013: Information technology-object management group business process model and notation

7. ISO/IEC 19514:2017: Information technology-object management group systems modeling language (OMG SysML)
8. Open Group Standard Reference C162:2016: ArchiMate ${ }^{\circledR} 3.0$ specification. https://publications.opengroup.org/c162. Accessed 21 Aug 2018

9. Siau, K., Rossi, M.: Evaluation techniques for systems analysis and design modelling methods - a review and comparative analysis. Inf. Syst. J. 21(3), 249-268 (2011)

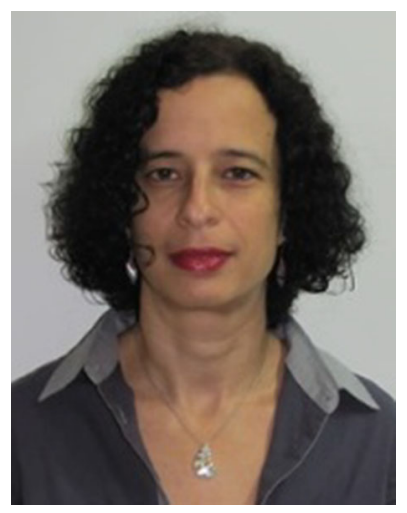

Iris Reinhartz-Berger is a faculty member at the Department of Information Systems, University of Haifa, Israel. She received her MSc and Ph.D. in Information Management Engineering from the Technion-Israel Institute of Technology - and her BSc in computer science and applied mathematics from the Technion-Israel Institute of Technology. Her research interests include conceptual modeling, domain analysis, modeling languages and techniques for analysis and design, and systems development processes. She coorganized a series of domain engineering workshops, in conjunction with the CAiSE conference, and co-edited a book entitled "Domain Engineering: Product Lines, Languages, and Conceptual Models." She co-chairs EMMSAD-Exploring Modeling Methods for Systems Analysis and Development since 2017.

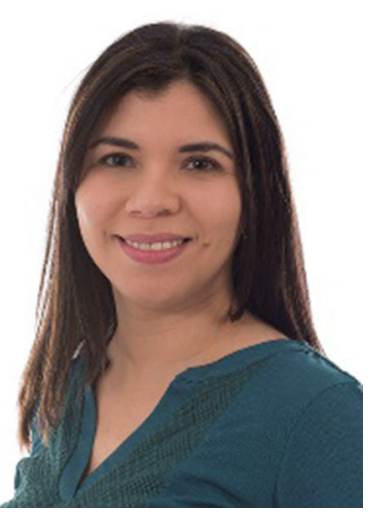

Wided Guédria is a senior researcher in the IT for Innovative Services (ITIS) department/Trusted Service Systems (TSS) unit, at the Luxembourg Institute of Science and Technology (LIST), as part of the iSEE research group focusing on modeling and improvement of service-intensive systems. She is also research associate at the Research Centre for Automatic Control (CRAN). Her main research topics concern interoperability, systemic modeling, enterprise architecture, informed design and informed decision making. Dr Guédria received her Ph.D. in production engineering, automatic and signal processing, from the University of Bordeaux 1, France, in 2012. She is scientific leader and Coordinator of the TG1 e-Health in Interop/vlab and member of the scientific advisory and management board of the INTEROP-Grande Région, France. Dr. Guédria is also the Luxembourg expert for CEN/TC 310 WG1 (advanced manufacturing technologies) at L'Institut luxembourgeois de la normalisation, de l'accréditation, de la sécurité et qualité des produits et services (ILNAS) and member of the international working group IFIP WG8.1, focusing on the planning, analysis, design and evaluation of information systems of organizations. 


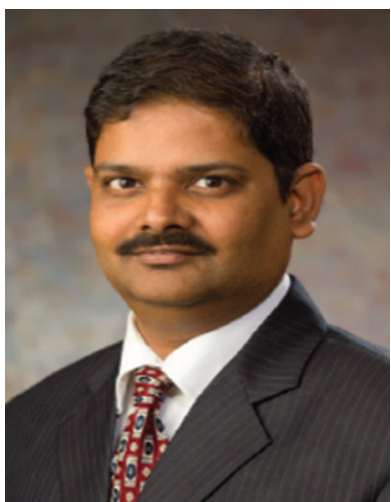

Palash Bera is an Associate Professor and Father Davis Professor of Richard A. Chaifetz School of Business Saint Louis University, USA. His research interests are in empirical studies in systems analysis and design and predictive analytics. He has published in top information systems journals such as MIS Quarterly, Information Systems Research and Communications of the ACM. 